\title{
Política industrial e desenvolvimento regional: convergência entre a Política de Desenvolvimento Produtivo, o Plano Brasil Maior e o Polo Industrial de Manaus
}

\author{
Huascar Fialho Pessali* \\ Walter Tadahiro Shima**
}

\section{Resumo}

O artigo avalia a existência de sobreposição de alvos entre o desenho das políticas industriais (PDP e PBM) e a política de desenvolvimento regional dirigida ao Polo Industrial de Manaus (PIM). Verifica-se que parte dos segmentos industriais do PIM é contemplada no PDP e no PBM, a maioria dos quais com elos produtivos intensivos em escala, dependentes em conhecimento e inovação, e usuários vorazes do complexo eletrônico. Este complexo, de maior potencial inovativo e de spillover, se desenvolveu limitadamente no PIM e em outras regiōes do país, guardando suas competências centrais nas matrizes. As etapas produtivas localizadas no PIM, embora de indústrias com razoáveis inovatividade e resposta à renda, são pouco intensivas em conhecimento e inovação locais. Os esforços para incorporar maior intensidade de P\&D e inovação aos elos produtivos do PIM têm se concentrado nas instituições da política regional.

PalaVras-Chave | Política Industrial; Política de Desenvolvimento Produtivo; Plano Brasil Maior; Polo Industrial de Manaus; Convergência

Códigos JEL | L; L5; L52

* Os autores agradecem o apoio financeiro do CNPq e do Ipea. Agradecem também a José Alberto da Costa Machado, à Superintendência da Suframa nos anos de 2011 e 2012, ao engenheiro de projetos Wagner Jun e aos pareceristas da RBI, isentando-os de qualquer responsabilidade sobre o texto aqui publicado.

** Universidade Federal do Paraná (UFPR), Curitiba (PR), Brasil. E-mail: pessali@ufpr.br

*** Universidade Federal do Paraná (UFPR), Curitiba (PR), Brasil. E-mail: waltershima@ufpr.br 


\title{
The convergence between industrial and regional development policies in the Industrial Cluster of Manaus
}

\begin{abstract}
Industrial and regional development policies may create synergic effects when designed to overlap. Here we study the case involving the design of two recent Brazilian industrial programs (PDP and PBM) and a long established regional development project (PIM - the Industrial Cluster of Manaus). Nominally, PDP and PBM include most of PIM industries. Within that group, most local production stages are scale intensive, dependent on exogenous innovation, and intensive demanders of the electronic industries. The latter industries, with greater potential for innovation and technological spillovers, have developed only partially in PIM and other Brazilian regions. They are mostly branches of international firms that keep core competences in their headquarters. Although PIM industries in the overlapping set of policies are innovative and respond reasonably to income, their local production stages are not intensive in local innovation and knowledge. Efforts to intensify R\&D and innovation therein have emerged mostly from regional development institutions alone.
\end{abstract}

KeYwords | Industrial Policy; Productive Development Policy; Brasil Maior Plan; Industrial Pole of Manaus; Policy Convergence

JEL-CODES | L; L5; L52 


\section{Introdução}

Há momentos na história em que iniciativas importantes como políticas de desenvolvimento regional e políticas industriais são deixadas de lado. Os motivos para isso vão desde políticas monetárias de curto prazo até o argumento clássico do laissez-faire, como no Brasil dos anos 1990 e início dos 2000. Há outros momentos em que tais iniciativas ganham massa crítica suficiente para retornar à ordem do dia. Tem crescido no Brasil, a partir de meados da década de 2000, o entendimento de que ambas as iniciativas possuem espaço. A título de ilustração, citam-se o restabelecimento da Superintendência de Desenvolvimento do Nordeste - Sudene e da Superintendência de Desenvolvimento da Amazônia - Sudam, em 2003, o Programa de Aceleração do Crescimento e o lançamento da Política de Desenvolvimento Produtivo, em 2007, e o Plano Brasil Maior, em 2011, todos sob a batuta do Ministério do Desenvolvimento, Indústria e Comércio Exterior.

$O$ recrudescer de tal entendimento e sua aplicação com iniciativas concomitantes, porém, não vêm sem desafios. Um deles é a necessidade de coordenação entre elas num ambiente econômico complexo (WALDROP, 1992; COOKE, 2012). A maior complexidade exige mecanismos materiais e institucionais novos, mais sofisticados, para lidar com tal desafio e dele tirar proveitos (CHANG, 2012).

Este texto busca ilustrar um caso de complexidade em que a convergência de alvos de políticas diferentes pode potencializá-las. Uma é o esforço de longa data da Superintendência da Zona Franca de Manaus - Suframa em fixar e expandir uma base de atividade industrial na Amazônia ocidental, tentando aproximar a economia da região à do restante do país. Isso envolveu a criação da Zona Franca de Manaus (ZFM) em 1957, reformulada e ampliada em 1967, dando origem ao Polo Industrial de Manaus (PIM), o maior polo industrial da Região Norte com aproximadamente 600 empresas industriais (SUFRAMA, 2013a). Outra é a Política de Desenvolvimento Produtivo (PDP) e o subsequente Plano Brasil Maior (PBM) que a absorveu. O desafio da coordenação é explicitado no desenho de governança da PDP, mostrando preocupação com a "convergência com outros programas do atual Governo" (BRASIL, 2009).

As duas iniciativas são em si bastante complexas. Cada uma envolve programas e projetos que se ramificam em várias linhas de interesse e ação. Há, portanto, um desafio de coordenação vertical dentro de cada uma. Não bastasse isso, existe ainda um desafio de coordenação horizontal entre elas. Em outras palavras, pode ser que seus esforços se sobreponham, levem a direções diferentes, ou mesmo se choquem. 
Este é o espectro de convergência aqui tratado. Adicionalmente, o recorte desse estudo requer considerar duas situaçōes de partida. Primeiro, a existência de uma política de desenvolvimento regional com atividade industrial indica a heterogeneidade do desenvolvimento industrial brasileiro em termos territoriais. Segundo, uma política industrial de qualquer natureza atinge setores desigualmente distribuídos no espaço nacional. A questão da coordenação horizontal então se refina: em que medida os esforços convergem para se complementarem ou se potencializarem em prol do desenvolvimento industrial de uma localidade?

Para lidar com essa questão, no presente artigo é feita inicialmente uma exposição da PDP e do PBM em seus desenhos. Em seguida, apresentam-se o desenvolvimento recente do PIM e o desempenho de seus segmentos industriais mais importantes. Posteriormente, é discutida a convergência entre as políticas, numa tentativa de avaliar em que direção pode haver potencialização dos esforços de desenvolvimento do PIM. Por fim, seguem os comentários finais.

\section{A PDP, o PBM e o desenvolvimento regional}

Uma das controvérsias inerentes a qualquer política industrial é a combinação de sua amplitude e profundidade em termos setoriais. A horizontalidade de uma política caracteriza a extensão desejada de atingir um amplo espectro da, senão idealmente toda, atividade industrial sem priorizar segmentos. Em princípio, ações horizontais pretendem ser neutras em termos da distribuição de custos e benefícios da política, pelo menos dentro do setor industrial. Em termos territoriais, a neutralidade se expressa de modo diferente. Com açôes horizontais, o estímulo à expansão industrial se concentra na indústria já existente e suas decisões de localização dos investimentos não são, teoricamente, afetadas pela política. Apenas a combinação com fatores em princípio exógenos à política, como deseconomias de aglomeração ou crescimento de mercados distantes, pode alterar tal cenário. Para o propósito do desenvolvimento que reduz desigualdades regionais, portanto, as ações horizontais não prometem efeitos sinérgicos relevantes.

A verticalidade de uma política caracteriza a extensão em que se quer atingir um ou alguns ramos de atividade de modo a promovê-los com maior intensidade. Logo, as ações verticais de uma política industrial podem favorecer um segmento com representatividade numa dada regiáo. Ao se considerar um território em situação desfavorável quanto a parâmetros relevantes de desigualdade socioeconômica, um efeito das açôes verticais pode ser a promoção da atividade industrial local e, 
por conseguinte, a expansão de sua renda. Ao contrário, dependendo das escolhas feitas, tal território pode ficar alheio ao impacto das açóes verticais e ver piorar sua situação em termos de desigualdade. $\mathrm{O}$ aspecto vertical das ações de política industrial apresenta, portanto, efeitos de maior interesse à questão das desigualdades regionais, ao permitir maior flexibilidade para ações mais diretas e pontuais no que se refere aos instrumentos, aos fins e aos beneficiários da política.

Uma combinação da extensão e da seleção dos setores caracteriza a transversalidade de uma política industrial. A PDP, nesses termos, tem visíveis características transversais. Ela foi anunciada em 2007, oficialmente concluída em 2010 e integrada ao PBM em agosto de 2011 (BRASIL, 2012b), o qual afirma dar continuidade à PDP com adaptações. Ambos abordam uma estrutura industrial brasileira diversificada, cujos setores precisam de atendimentos idiossincráticos de acordo com sua capacidade de gerar externalidades positivas e com sua deterioração ao longo de mais de 20 anos de ausência de política industrial. Ressalvamos que os determinantes da escolha e alocação dos setores dentro dos Programas da PDP ou do PBM, bem como os problemas de sua implementação, não são alvo de discussão deste artigo.

A PDP foi elaborada sobre três eixos de ação, denominados Programas Estruturantes e identificados em: "fortalecimento para a competitividade"; "mobilizadores em áreas estratégicas"; e "consolidar e expandir a liderança." Neles foram situados os setores industriais alvejados. No PBM os eixos de ação foram redefinidos com base em cinco diretrizes estruturantes (DE): "fortalecimento das cadeias produtivas"; "consolidação de competências na economia do conhecimento natural"; "ampliação e criação de novas competências tecnológicas e de negócios"; "desenvolvimento das cadeias de suprimento em energias"; e "diversificação das exportações (mercados e produtos) e internacionalização corporativa" (BRASIL, 2012b).

As cinco diretrizes estruturantes do PBM detalham e verticalizam melhor os objetivos da política industrial por atividade. Desse modo, por exemplo, no segmento têxtil e confecções, o fortalecimento da competitividade significa, antes de tudo, o fortalecimento da sua cadeia produtiva. Já o fortalecimento da competitividade em bens de capital implica ampliar/criar novas competências tecnológicas. Além disso, o PBM foi mais explícito em duas áreas que estavam no conjunto de atividades de um dos eixos da PDP e que passaram a ser DE: as de cadeias de suprimento de energias e a de competências na economia do conhecimento natural.

Perpassando a dimensão setorial, vale antecipar que a PDP adicionou um programa com seis destaques estratégicos, sendo um deles a regionalização das iniciativas. A este respeito, o Ministério do Desenvolvimento, Indústria e Comér- 
cio Exterior - MDIC sinalizou o seguinte: "O foco das ações que compõem este programa, que estará articulado à Política Nacional de Arranjos Produtivos Locais, é a promoção de atividades produtivas no entorno de projetos industriais e de infraestrutura. Uma de suas metas é ampliar a participação dos financiamentos do BNDES à Região Nordeste até 2010" (BRASI, s/d “a”). A regiāo Norte e o PIM não recebem menção explícita. O PBM, na sequência, foi anunciado como "a política industrial, tecnológica, de serviços e de comércio exterior do Governo Federal para o período de 2011 a 2014" (BRASIL, s/d "b"). Nele foi constituída a Coordenação Sistêmica de Ações Especiais em Desenvolvimento Regional, com vistas a articular a territorialização do Plano. A Coordenação programou atividades de mobilização e debate até o final de 2013. Até novembro de 2014 não havia registro de divulgação dos resultados de tais atividades. Embora aparentemente permeáveis ao preceito do desenvolvimento regional, nem a PDP nem o PBM parecem ter incorporado explícita ou formalmente categorias e instrumentos a ele relacionados e que moldassem substancialmente suas arquiteturas.

\section{Caracterização do Polo Industrial de Manaus}

As políticas regionais de desenvolvimento assumem que os territórios partem de dotações de recursos e estruturas socioeconômicas heterogêneas, criando padróes de reprodução social díspares. Alguns deles conseguem gerar maior bem-estar material do que outros. Isso leva ao aumento das disparidades, que passa a ser identificado como um problema a demandar açóes cujos efeitos, espera-se, ajudem a melhorar os padrōes de reprodução social das regiôes menos desenvolvidas. Em geral, essa tentativa de modificação estrutural do território requer a ação de um ente nacional que tenha alguma autonomia com relação ao padrão que se quer modificar. Não fosse assim, sua competência e disposição para uma mudança bem-sucedida ficariam em xeque. Um exemplo de tal lógica está na estruturação das Superintendências Regionais de Desenvolvimento no Brasil.

Ao mesmo tempo, a dinâmica do conhecimento aplicado à esfera produtiva $\mathrm{e}$ ao uso de recursos faz com que os potenciais de cada território possam ser revistos oportunamente. Uma região pouco promissora pode se tornar mais promissora em função dos recursos humanos e materiais ali existentes ou construídos em conexão com os desenvolvimentos de outras partes ou áreas dos sistemas econômicos. Isso parece ser percebido ciclicamente pelos estudiosos do tema e fez ressurgir nas últimas décadas o interesse pelas regiôes como detentoras de qualidades peculiares 
com potencial alcance global (COOKE, 1992; MORGAN, 1997; MASKELL; MALMBERG, 1999).

Estas visões convergem para uma preocupação com o desenvolvimento da Região Norte do Brasil. Por um lado, há hoje o resultado do esforço de se levar a atividade industrial à Região. Isso se deu, principalmente, por meio do modelo da ZFM, cujo maior feito está concretizado no PIM. Por outro lado, há uma percepção difundida de que fatores como a biodiversidade e o conhecimento local sobre a mesma têm um potencial econômico não desprezível (BECKER, 2005). Vislumbra-se que tais elementos podem ser associados a novas competências e atividades industriais com alcance global (LASMAR, 2005).

Assim, a Região insiste nos mecanismos de atração existentes para conseguir novos investimentos e dar sobrevida às políticas existentes, como a do PIM. Em 1970, Manaus não aparecia no mapa de aglomerados industriais relevantes do Brasil, mas daquele ano até 1985 registrou a maior variação positiva de participação no emprego industrial brasileiro, com uma taxa média de crescimento anual próxima a 9\% (DINIZ; CROCCO, 1996). Tal evolução, porém, é qualificada por Lemos et al. (2003, p. 693): “a transformação do 'enclave industrial' de Manaus em 'região isolada industrial' não muda a natureza da caracterização da indústria local, no que toca à falta de ancoragem territorial, refletindo muito mais a maior concentração de produtos eletrônicos de consumo atraídos pela continuidade da política de incentivos fiscais." Ou seja, a consolidação do PIM não venceu as lacunas estruturais que dificultam seu catching up com relação às regiōes mais ricas do país. Em 2014, o Congresso Nacional prorrogou até 2073 o regime de incentivos fiscais especiais da ZFM (BRASIL, 2014b), quando completará 106 anos de vigência.

O modelo teve uma adaptação relevante no início dos anos 1990, numa tentativa de estancar e quiçá reverter a lógica que lá se estabeleceu da montagem de componentes importados e de local de passagem de insumos de outras regióes. Com a Lei n. 8.387/1991, as atividades industriais da ZFM passaram a ser orientadas pelo Processo Produtivo Básico (PPB), o qual constitui "o conjunto mínimo de operações, no estabelecimento fabril, que caracteriza a efetiva industrialização de determinado produto" (BRASIL, 2011a). Ele é estabelecido por um grupo de trabalho (GT-PPB) composto por membros do MDIC e MCT e que negocia com os setores produtivos interessados em produzir no PIM a partir de discussões técnicas sobre processos industriais. O first-mover do PPB é, em geral, uma empresa interessada e sua proposta é submetida aos demais concorrentes no país. Pode haver nela, por exemplo, a indicação de competências técnicas que os concorrentes não possuem, 
ou não possuem no país. A partir disso são sugeridas etapas produtivas a serem feitas localmente em função da competência da indústria nacional e dos objetivos de política incorporados pelos ministérios envolvidos, que são então negociadas entre os concorrentes. Quando se chega a um consenso sobre isso, o GT-PPB propõe a vigência do instrumento legal - uma portaria interministerial - que vincula o PPB aos benefícios fiscais e vale para todas as empresas, a proponente e as concorrentes.

Quanto maiores as expectativas de vantagens, maior é o interesse em se propor novos PPB. Estas vantagens podem vir, por exemplo, da redução de custos em relação aos componentes feitos no exterior, por meio da importação de máquinas e equipamentos usados ou da utilização de tecnologias intensivas em mão de obra barata, da oportunidade de renovar linhas de produção e associar seu melhor desempenho aos benefícios fiscais, ou de novas capacitações locais (FERREIRA; BOTELHO, 2014). Em termos gerais, são fatores que melhoram a competitividade do proponente e, porventura, das demais empresas via PPB.

Considerando-se este esforço particular de desenvolvimento da atividade industrial na Região, cabe agora apresentar algumas características do PIM. Segundo a classificação da Suframa (2009b), ele é composto pelos subsetores listados na Tabela 1. As colunas à direita apresentam as respectivas taxas de crescimento anual composto (TCAC) do faturamento dos segmentos entre 1998 e 2013 em três localidades: no PIM, no resto do Brasil e nas exportações brasileiras. ${ }^{1}$

Dos sete maiores subsetores em faturamento, seis apresentaram as maiores TCAC dentro do PIM. Eles também têm, na maioria, as maiores TCAC de faturamento no resto do Brasil e nas exportações brasileiras (exceto papel e papelão). Isso sugere que tais subsetores cresceram não necessariamente apenas pelas condições favoráveis do Polo, mas também por acompanharem a dinâmica que moveu as empresas dos mesmos subsetores no resto do país e as suas exportaçōes.

A exceção é o subsetor eletroeletrônico. Embora historicamente o de maior peso no PIM, ele teve uma TCAC inferior a outros subsetores menores do Polo. $\mathrm{Na}$ indústria eletroeletrônica mundial tem havido concentração, aumento da produtividade por meio da redução de custos e da elevação das escalas de produção e continuada incorporação de seus produtos a outros produtos finais e aos processos produtivos. No Brasil isso seu deu de forma mais intensa após a maior abertura comercial dos anos 1990, quando diversas empresas internacionais se instalaram principalmente em São Paulo e no PIM (CUNHA, 2003; PERTICARRARI, 2003).

1 TCAC $=\left\{[(\text { valor final }) /(\text { valor inicial })]^{\wedge}(1 / \mathrm{n})\right\}-1 ;$ em que $\mathrm{n}=$ número de anos. 
TABELA 1

Participação no faturamento total do PIM e taxas de crescimento anual composto (TCAC) (1) do faturamento, por localidade, segundo subsetores do PIM - 1988-2013

Em porcentagem

\begin{tabular}{|c|c|c|c|c|}
\hline \multirow[b]{2}{*}{ Subsetores do PIM } & \multirow{2}{*}{$\begin{array}{l}\text { Participação no } \\
\text { faturamento } \\
\text { total do PIM } \\
\text { em } 2013\end{array}$} & \multicolumn{3}{|c|}{ TCAC do faturamento - 1988-2013 } \\
\hline & & No PIM & $\begin{array}{l}\text { No resto } \\
\text { do Brasil }\end{array}$ & $\begin{array}{c}\text { Das exportaçóes } \\
\text { totais (PIM+Brasil) }\end{array}$ \\
\hline Eletroeletrônico & 33,96 & 5,45 & 7,90 & 12,98 \\
\hline Duas rodas & 17,05 & 11,47 & 11,38 & 12,17 \\
\hline Químico & 12,45 & 23,22 & 25,45 & 46,83 \\
\hline Bens de informática & 16,72 & 23,38 & ND & ND \\
\hline Metalúrgico & 4,24 & 11,37 & 10,55 & 4,28 \\
\hline Termoplástico & 4,91 & 11,16 & 13,75 & 22,24 \\
\hline Mecânico & 4,75 & 17,96 & 18,25 & 23,30 \\
\hline $\begin{array}{l}\text { Isqueiros, canetas e } \\
\text { barbeadores descartáveis }\end{array}$ & 2,17 & 7,86 & 8,69 & 1,79 \\
\hline Relojoeiro & 1,54 & 4,93 & 5,14 & $-2,18$ \\
\hline Outros (2) & 1,22 & 1,33 & ND & ND \\
\hline Bebidas & 0,70 & 6,51 & ND & ND \\
\hline Mineral não metálico & 0,44 & 5,19 & ND & ND \\
\hline Papel e papelão & 0,47 & 8,10 & 3,84 & 30,21 \\
\hline Ótico & 0,38 & 5,29 & 5,65 & 5,04 \\
\hline Brinquedos & 0,12 & 1,30 & ND & ND \\
\hline Madeireiro & 0,08 & $-2,86$ & $-7,33$ & $-1,28$ \\
\hline Total & 100,00 & & - & - \\
\hline
\end{tabular}

Fonte: Suframa (2010, 2013b).

(1) Todas as TCAC foram calculadas com base nos valores absolutos constantes em Suframa (2010, 2013b).

(2) Composto pelos subsetores: couros e similares; material de limpeza; produtos alimentícios; editorial e gráfico; mobiliário; beneficiamento de borracha; naval e diversos. Dados disponíveis até 2010. Este valor não compõe o total de $100 \%$. $\mathrm{ND}=$ não disponível.

A expansão do setor é sinalizada pela TCAC do faturamento no resto do Brasil e pela TCAC do faturamento das exportaçóes, maiores do que sua TCAC do faturamento no PIM, indicando que houve maior crescimento em outras regiōes e pelas exportações. Isso sugere uma maior alocação de elos da cadeia fora do PIM e um relativo aumento da competitividade da indústria nacional, ao faturar mais com exportaçôes num momento de relativa estabilidade cambial. ${ }^{2}$ Nesse caso, mesmo

2 Em valores absolutos, a participação do faturamento do resto do país no faturamento total do setor vai de $76 \%$ em 1988 a 90\% em 2013; no mesmo período, o PIM passa de $24 \%$ para $9 \%$, e as exportaçōes de $0,20 \%$ para $0,73 \%$. Ou seja, apesar do crescimento na relevância relativa das exportaçóes no faturamento total, elas têm pequena participação no faturamento total absoluto. Além disso, seu comportamento é errático ao longo da série (e.g. em 2002 chegaram a 16\%, caindo brutalmente em seguida) (SUFRAMA, 2013b). 
com um crescimento equânime da produção em todos os elos, o crescimento do faturamento distribuir-se-ia em favor dos elos produtivos situados fora do PIM. A dinâmica de localização deste segmento, portanto, parece ter sido pouco afetada pelo que ofereceu o PIM no período contemplado pelos dados (1988-2013). Tal situação tanto alerta para a necessidade de uma interseção das políticas industrial e de incentivos da ZFM que considere a recuperação regional, quanto mostra o aumento do desafio a ser vencido.

O Gráfico 1 ilustra a liderança histórica do subsetor eletroeletrônico no faturamento do PIM e também a perda de sua importância relativa perante subsetores como os de duas rodas, químico, bens de informática, metalúrgico e termoplástico. Como já visto, esses subsetores tiveram TCAC mais elevadas ao longo do período 1988-2013.

\section{GRÁFICO 1}

Evolução da participação dos principais subsetores no faturamento total do PIM - 1988-2013

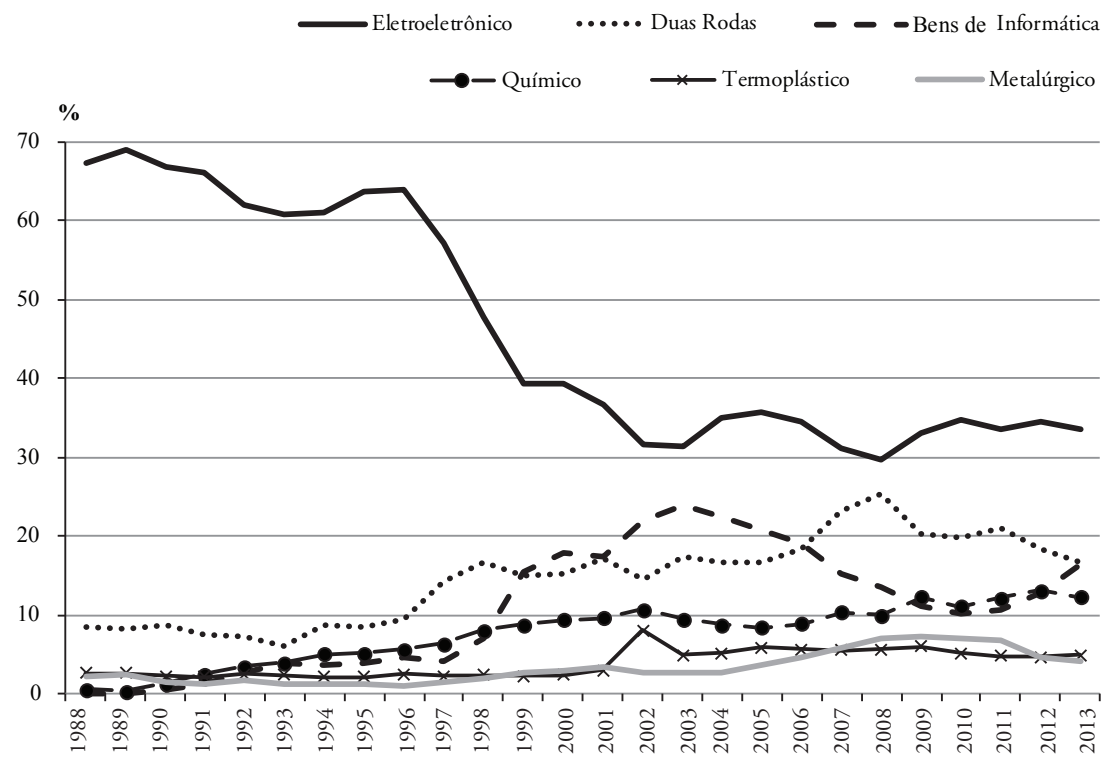

Fonte: SUFRAMA (2010, 2013b).

Dentro dos subsetores, os segmentos com maior TCAC (destacados no Quadro 1) pertencem a indústrias que tiveram grande expansão no período em análise. Vários segmentos dos subsetores eletroeletrônico, duas rodas e bens de informática se instalaram ou expandiram sua produção no país a partir da estabilização de pre- 
ços em meados dos anos 1990. Do mesmo modo, é a partir dali que se expandem a telefonia móvel, o uso da Internet (com a difusão do uso de computadores) e a digitalização de mídias. A partir de meados dos anos 2000, foi a vez dos televisores de tela plana. Ou seja, apesar do período não ter sido de expansão geral da economia brasileira, nele se viu difundir novas tecnologias de base microeletrônica que permeiam outros subsetores relevantes do PIM.

QUADRO 1

Subsetores mais relevantes do PIM e respectivos segmentos

\begin{tabular}{|l|l|}
\hline \multicolumn{1}{|c|}{ Subsetores } & \multicolumn{1}{c|}{ Segmentos } \\
\hline \multirow{4}{*}{ Eletroeletrônico } & Aparelho de ar-condicionado \\
& Aparelhos de som 3 em 1 (1) \\
& Aparelhos transmissores/receptores \\
& DVD player \\
& Rádio gravador tape deck \\
& Receptor decodificador de sinal digitalizado \\
& Telefone celular \\
& TV em cores \\
\hline \multirow{2}{*}{ Duas rodas } & Bicicletas \\
& Motocicletas \\
\hline \multirow{3}{*}{ Bens de informática } & Compact disc \\
& DVD \\
& Microcomputador \\
& Monitores de vídeo \\
\hline Químico & Concentrados químicos para bebidas não alcoólicas \\
\hline Termoplástico & Aparelhos de barbear não elétricos \\
\hline Metalúrgico & Lâminas de barbear \\
\hline
\end{tabular}

Fonte: Suframa (2013b). Elaboração dos autores.

(1) A Suframa (2013b) ainda usa a classificação Aparelhos de som $3 \mathrm{em} \mathrm{1,} \mathrm{Rádio} \mathrm{gravador} \mathrm{tape} \mathrm{deck} \mathrm{e} \mathrm{TV} \mathrm{em} \mathrm{cores.} \mathrm{Com} \mathrm{a}$ convergência digital, os dois primeiros foram substituídos por tocadores de música em meio eletrônico (e.g. $m p 3$ players). Já as TVs não mais se diferenciam pelas cores das imagens. O que supostamente ocorre é que os fabricantes dos antigos bens permanecem nas categorias existentes para fins de benefícios fiscais por fabricarem os produtos que os sucederam.

Cabe adicionar à lista de segmentos relevantes o de biocosméticos, que, segundo a Suframa (2009a), tem caráter estratégico. Seu PPB foi implementado em 2007 e trouxe expectativas positivas em função da alta elasticidade-renda de seus produtos. Há, porém, muitas incertezas com relação à regulação do acesso aos recursos naturais e seus componentes moleculares, bem como aos conhecimentos tradicionais associados aos mesmos (AZEVEDO, 2005). Interesses empresariais, por sua vez, têm se manifestado contrários à ampliação da cadeia produtiva local e favoráveis à sua alocação próxima a centros consumidores (RIOS, 2012). 


\section{A convergência entre as políticas}

Tendo sido apresentada a abrangência do desenho das duas políticas, busca-se agora dimensionar o quanto elas coincidem. Há em termos lógicos três situações possíveis. A primeira é o conjunto interseção, que indica o espectro de potencialização da política industrial sobre a política regional que, neste caso, a precedeu e constituiu um conjunto localizado de atividades industriais. A segunda compreende o conjunto de segmentos contemplados pela política industrial mas não situados no PIM. Neste caso, a motivação para que tais segmentos considerem o PIM para sua instalação é, na melhor das situações, provocada apenas pelos atrativos da política regional. E a terceira é o conjunto de segmentos trabalhados apenas pela política regional, que continuará a depender dos esforços locais e dos instrumentos já existentes, sem perspectiva de potencializar seu avanço por meio da política industrial. Isso pode levar a política regional a se mover na direção da interseção com outras políticas de cunho não regional ou a promover os segmentos situados no segundo conjunto. Essa possibilidade, porém, pode colocar o PIM em disputa com as regiões onde os segmentos já estejam instalados.

A sobreposição dos segmentos industriais alvejados pelas duas políticas será considerada, principalmente, em termos de seu potencial de gerar mudança técnica, uma das principais fontes de competitividade da indústria. Para tanto, seguiremos a classificação consagrada de Pavitt (1984). Segundo o autor, os segmentos industriais classificam-se em quatro categorias relacionadas à natureza da atividade inovativa:

- supplier-dominated - empresas com pouco investimento em P\&D, geralmente em setores tradicionais da manufatura. Sua trajetória tecnológica tem foco na redução de custos e, em geral, incorporam inovaçôes externas ao seu segmento;

- scale-intensive - grandes empresas produzindo materiais básicos e bens de consumo duráveis. As fontes de inovação são internas e externas ao segmento e possuem um grau médio de apropriabilidade;

- specialized suppliers - empresas especializadas em produzir tecnologias para outras firmas (e.g. máquinas especiais e instrumentos de alta tecnologia), com alto nível de apropriabilidade e elevado nível de conhecimento tácito;

- science-based - empresas de alta tecnologia intensiva em P\&D interno e externo e conhecimento tácito. Elas têm relação próxima com pesquisas nas universidades e alto grau de apropriabilidade por meio de patentes e segredo industrial. 
O Quadro 2 traz, em sua primeira coluna, os segmentos industriais de maior peso no PIM (SUFRAMA, 2009b) adicionados do segmento nascente de biocosméticos. A segunda e a terceira colunas os situam dentro dos programas/subprogramas da PDP e das diretrizes do PBM. A quarta coluna situa a indústria como um todo na taxonomia de Pavitt (1984) e a quinta coluna faz o mesmo com os elos produtivos das indústrias situados no PIM.

Verifica-se que boa parte dos principais segmentos industriais do PIM é contemplada no programa Fortalecer a Competitividade, subprograma Eletrônica de Consumo (linha branca, linha marrom e portáteis). O segmento de biocosméticos se encaixa no subprograma Higiene Pessoal, Perfumaria e Cosméticos e o de motocicletas no Complexo Automotivo. Os segmentos aparelhos transmissores/receptores e receptor/ decodificador de sinal digitalizado do PIM encaixam-se no programa Mobilizadores em Áreas Estratégicas, via subprograma TIC/Infraestrutura para Inclusão Digital. Outros segmentos, como aparelhos de barbear não elétricos, bicicleta, concentrados químicos para bebidas não alcoólicas e lâminas de barbear, não são mencionados na PDP e no PBM. No PBM a interseção fica concentrada em duas diretrizes estruturantes: diversificação das exportaçōes (mercados e produtos) e internacionalização corporativa e ampliação e criação de novas competências tecnológicas e de negócios.

Consideremos o que se refere à taxonomia de Pavitt (1984). Os segmentos industriais enquadrados no programa/subprograma Fortalecer a Competitividadel Eletrônica de Consumo são, em sua natureza, science-based. Isso não quer dizer, porém, que sua cadeia produtiva na íntegra também o seja. No caso do PIM, o PPB tenta garantir e ampliar um grupo mínimo de atividades da cadeia. Historicamente, boa parte da indústria no PIM utiliza o mecanismo para melhorar sua produtividade o suficiente para atender ao mercado nacional, aproveitando os benefícios fiscais, visto o discreto desempenho de suas exportaçōes (DINIZ, 2008). Em outros termos, tem-se uma produção local por empresas multinacionais que, entre 1998 e 2010, responderam por aproximadamente $27 \%$ do valor dos insumos utilizados no produto final (SUFRAMA, 2010). No subsetor de eletroeletrônicos, esse índice médio de regionalização dos insumos cai para 23\% (SUFRAMA, 2010). A partir do recebimento de componentes universais, os elos da cadeia produtiva no PIM atuam mais numa lógica de produção scale-intensive para atender às especificidades do mercado nacional, como nos processos CKD e SKD. ${ }^{3}$ Há neles pouco espaço para atuar

3 CKD (completely knocked down ou complete knock-down) refere-se ao kit completo de um produto que precisa ser montado. O kit costuma ser importado e montado no país e as empresas, a depender da legislação, podem vendê-lo como produto nacional. SKD (semi knocked-down) refere-se ao kit incompleto. 
QUADRO 2

Segmentos industriais relevantes do PIM enquadrados de acordo com a PDP, PBM e taxonomia de Pavitt (1984)

\begin{tabular}{|c|c|c|c|c|}
\hline \multirow{2}{*}{$\begin{array}{c}\text { Segmentos } \\
\text { industriais de } \\
\text { maior peso no PIM } \\
\text { (SUFRAMA, 2009b) }\end{array}$} & \multirow{2}{*}{$\begin{array}{c}\text { Enquadramento } \\
\text { em programas e } \\
\text { subprogramas da } \\
\text { PDP }\end{array}$} & \multirow{2}{*}{$\begin{array}{l}\text { Enquadramento } \\
\text { nas diretrizes } \\
\text { estruturantes do } \\
\text { PBM }\end{array}$} & \multicolumn{2}{|c|}{$\begin{array}{l}\text { Classificaçáo de acordo com a } \\
\text { taxonomia de Pavitt (1984): }\end{array}$} \\
\hline & & & $\begin{array}{l}\text { Indústria na } \\
\text { cadeia global } \\
\text { de valor }\end{array}$ & $\begin{array}{l}\text { Os elos dessa } \\
\text { indústria } \\
\text { instalados no } \\
\text { PIM }\end{array}$ \\
\hline Motocicletas & $\begin{array}{l}\text { Fortalecer a com- } \\
\text { petitividade: com- } \\
\text { plexo automotivo }\end{array}$ & $\begin{array}{l}\text { Diversificação das } \\
\text { exportaçôes (mer- } \\
\text { cados e produtos) } \\
\text { e internacionaliza- } \\
\text { ção corporativa }\end{array}$ & $\begin{array}{l}\text { Supplier-domi- } \\
\text { nated }\end{array}$ & \\
\hline $\begin{array}{l}\text { Aparelho de ar-con- } \\
\text { dicionado }\end{array}$ & $\begin{array}{l}\text { Fortalecer a com- } \\
\text { petitividade: eletrô- } \\
\text { nica de consumo/ } \\
\text { linha branca }\end{array}$ & \multirow{14}{*}{$\begin{array}{l}\text { Ampliação e } \\
\text { criação de novas } \\
\text { competências } \\
\text { tecnológicas e de } \\
\text { negócios }\end{array}$} & \multirow{13}{*}{ Science-based } & \multirow{13}{*}{ Scale-intensive } \\
\hline $\begin{array}{l}\text { Aparelhos de som } 3 \\
\text { em } 1\end{array}$ & \multirow{8}{*}{$\begin{array}{l}\text { Fortalecer a } \\
\text { competitividade: } \\
\text { eletrônica de con- } \\
\text { sumo/linha marrom } \\
\text { (áudio e vídeo) }\end{array}$} & & & \\
\hline Compact disc & & & & \\
\hline $\begin{array}{l}\text { DVD (meio mag- } \\
\text { nético) }\end{array}$ & & & & \\
\hline DVD player & & & & \\
\hline Microcomputador & & & & \\
\hline Monitores de vídeo & & & & \\
\hline $\begin{array}{l}\text { Rádio gravador tape } \\
\text { deck }\end{array}$ & & & & \\
\hline TV em cores & & & & \\
\hline $\begin{array}{l}\text { Relógio de pulso e } \\
\text { bolso }\end{array}$ & \multirow{2}{*}{$\begin{array}{l}\text { Fortalecer a com- } \\
\text { petitividade: eletrô- } \\
\text { nica de consumo/ } \\
\text { portáteis }\end{array}$} & & & \\
\hline Telefone celular & & & & \\
\hline $\begin{array}{l}\text { Aparelhos transmisso- } \\
\text { res/receptores }\end{array}$ & \multirow{2}{*}{$\begin{array}{l}\text { Mobilizadores em } \\
\text { áreas estratégicas: } \\
\text { TIC/infraestrutura } \\
\text { para inclusão digital }\end{array}$} & & & \\
\hline $\begin{array}{l}\text { Receptor decodi- } \\
\text { ficador de sinal } \\
\text { digitalizado }\end{array}$ & & & & \\
\hline Biocosméticos & $\begin{array}{l}\text { Fortalecer a } \\
\text { competitividade: } \\
\text { higiene pessoal, } \\
\text { perfumaria e cos- } \\
\text { méticos } \\
\end{array}$ & & \multicolumn{2}{|c|}{$\begin{array}{l}\text { Atividade recente no PIM, } \\
\text { podendo desenvolver atividades } \\
\text { scale-intensive, mas com esforços } \\
\text { locais de P\&D (science-based) }\end{array}$} \\
\hline $\begin{array}{l}\text { Aparelhos de barbear } \\
\text { não elétricos }\end{array}$ & & & \multirow{2}{*}{$\begin{array}{l}\text { Supplier-domi- } \\
\text { nated }\end{array}$} & \multirow[t]{2}{*}{ Scale-intensive } \\
\hline Bicicleta & & & & \\
\hline $\begin{array}{l}\text { Concentrados quími- } \\
\text { cos para bebidas não } \\
\text { alcoólicas }\end{array}$ & & & \multirow[t]{2}{*}{ Scale-intensive } & $\begin{array}{l}\text { Supplier-domi- } \\
\text { nated }\end{array}$ \\
\hline Lâminas de barbear & & & & Scale-intensive \\
\hline
\end{tabular}

Fonte: Elaboração dos autores. 
numa perspectiva science-based. Isso sugere a falta de interesse em desenvolver P\&D no local com produção de novos conhecimentos que possam eventualmente gerar spillovers e externalidades no PIM. Tais projetos e processos destas multinacionais têm supervisão atenta das matrizes em suas estratégias de cadeias produtivas globais, tendo papel secundário em suas filiais nos países em desenvolvimento (SUZIGAN, 2008). Portanto, o que poderia ser science-based - com transbordamentos positivos na demanda e na criação locais de competências - manifesta-se majoritariamente em suas etapas scale-intensive da cadeia produtiva.

A industrialização brasileira, sustentada em grande parte por empresas multinacionais do segmento de bens de consumo duráveis, como é o caso de boa parcela dos segmentos que estão no PIM, não levou à institucionalização de P\&D local. Poucos foram os instrumentos de política industrial que incentivaram processos autônomos de P\&D e que, assim, intensificariam a proposição de PPB em tal direção. Os instrumentos de maior calibre foram lançados em 2001 - a Lei n. 10.176 e o Decreto Presidencial n. 3.800. Eles concediam redução de impostos às empresas de desenvolvimento ou produção de bens e serviços de informática e automação que investissem em atividades de P\&D em tecnologia da informação, e a estendiam às Regiōes Norte, Nordeste e Centro-Oeste por um período de três anos a mais que nas demais. Mudanças em 2006 mantiveram diferenciais positivos para as três regiōes (Decreto Presidencial n. 5.906) e fixaram montantes a se investir em P\&D na Amazônia pelas empresas para ter benefícios fiscais. A isso se somaram incentivos estaduais. Desde então, a Suframa tenta estimular P\&D na ZFM. Por exemplo, em 2002, foi criado o Centro de Biotecnologia da Amazônia (CBA) voltado à inovação tecnológica a partir da biodiversidade amazônica. Seu funcionamento tem sido limitado, porém, pela longa indefinição sobre sua natureza jurídica (MARIA, 2014). Em 2003 foi criado o Centro de Ciência, Tecnologia e Inovação do PIM (CT-PIM), voltado a projetos de microeletrônica, dentro de um projeto de Polo Tecnológico com previsão de implementação em 2018 (PORTAL BRASIL, 2014). Outros vários convênios e acordos foram firmados com vistas a intensificar atividades de P\&D no PIM, agregar valor e adensar as cadeias produtivas do Polo com base em inovação local, ou seja, promover atividades science-based nos seus elos.

Os segmentos motocicletas e linha marrom se instalaram no início da ZFM e a linha branca se instalou nos anos 1990 e 2000. Estes são segmentos industriais que, como um todo, se fortaleceram no período do "milagre econômico" (1968 a 1973), aproveitando a expansão do mercado de bens de consumo duráveis. Suas cadeias produtivas se firmaram no país e adaptaram-se à incorporação da microeletrônica em 
seus produtos. No PIM, por exemplo, entre 1998 e 2010, o segmento motocicletas teve índices médios de regionalização e de nacionalização de insumos de 40\% e 75\% (SUFRAMA, 2010). Suas exportações, no mesmo período, corresponderam a $4 \%$ do faturamento do total de segmentos (SUFRAMA, 2010), indicando sua natureza scale-intensive dimensionada ao mercado nacional e repassadora de inovações externas. O segmento da linha marrom, por sua vez, vive um período de intensa mudança tecnológica. Ele é parte importante do subsetor eletroeletrônicos, que, como visto, teve uma das menores TCAC do PIM entre 1998 e 2013. Embora ainda seja o de maior faturamento do PIM, a razão entre seu faturamento e o do segundo maior subsetor, o de duas rodas, caiu de 8 para 2. No mesmo período, seus índices de nacionalização e de regionalização passaram de $85 \%$ para $21 \%$ e de $39 \%$ para $18 \%$, (SUFRAMA, 2010, 2013b). A dinamização destes segmentos envolve a difícil tarefa de adaptá-los às novas formas de competição dentro do atual paradigma tecnológico, à entrada de fornecedores globais e de capitais externos e à extrema volatilidade do câmbio no Brasil (FERRARI FILHO; PAULA, 2006). Sua inclusão no programa Fortalecer a Competitividade da PDP ajudaria em sua manutenção, considerando-se a expansão recente da renda e dos mercados internos. Os demais segmentos não contemplados pela PDP e caracterizados como scale-intensive e supplier-dominated têm menor relevância em termos de intensidade tecnológica.

O segmento de biocosméticos explora a sintetização de essências a partir de substâncias naturais. Sendo possível aproveitar a biodiversidade local, a atividade pode se beneficiar da sobreposição de esforços das políticas para ganhar maior competitividade. Entretanto, o segmento é incipiente e conta com dois projetos em instalação que somam aproximadamente US\$ 1,1 milhão em investimento fixo (SUFRAMA 2009c). Embora haja grandes empresas multinacionais nesta indústria, boa parte delas conhecida pela produção de cosméticos tradicionais, há menor concentração e mais espaço para produtores nacionais e locais. Existem também expectativas de que a biodiversidade da flora amazônica seja capaz de gerar novos princípios ativos para uma bioindústria (que, além dos cosméticos, inclui fitoterápicos e alimentação). Isso pode, por um lado, aproximar o segmento de uma posição science-based, algo que o esforço em criar o CBA deixa claro. Por outro lado, dependendo da capacidade local de geração e apropriabilidade do conhecimento necessário para tanto, o segmento local pode se posicionar como supplier-dominated. Um dos condicionantes de P\&D nesta área é o marco regulatório. O tema da biodiversidade e seu aproveitamento é regido pela Medida Provisória n. 2.186-16/2001 (BRASIL, 2001), um instrumento criticado por ser restritivo demais à inovação e gerar incertezas jurídicas (FERREI- 
RA; SAMPAIO, 2013). Isso pode levar à instalação de agentes cuja dinâmica de localização seja fracamente ou em nada afetada pela política de atração do PIM como empresas certificadoras e de bioquímica elementar -, a demandar princípios ativos extraídos da biodiversidade local aos quais se agregará valor exogenamente.

Os dois segmentos enquadrados no programa Mobilizadores em Áreas Estratégicas: TIC/Infraestrutura para inclusão digital da PDP - aparelhos transmissores/receptores e receptor decodificador de sinal digitalizado - são, teoricamente, specialized-supplier e science-based. Eles fazem parte do núcleo do atual paradigma tecnológico e geram spillovers para os demais segmentos industriais. No PIM, porém, suas etapas de produção têm tecnologias vindas das matrizes, visando atingir um mercado interno agora maior, nos mesmos moldes das linhas branca e marrom. Isso os aproxima das características scale-intensive. Não parece ter crescido a autonomia dessa indústria para realizar P\&D no país e gerar conhecimento inédito. Estas são indústrias que devem crescer mais do que as demais na atual economia do conhecimento, sustentando ondas longas de crescimento ao produzirem conhecimentos técnicos e científicos a serem adaptados, aprimorados, desenvolvidos e aplicados nas demais indústrias. Entende-se, assim, que tais indústrias sejam consideradas estratégicas pela PDP para programas Mobilizadores e, mais, que sejam disponibilizados mais recursos no país para uma cadeia com elevado desenvolvimento em termos relativos.

Segundo o MDIC (BRASIL, 2008), tais programas Mobilizadores aplicam-se a áreas em que "a construção da competitividade está fortemente relacionada à superação de desafios científico-tecnológicos para a inovação, exigindo o compartilhamento de metas entre o setor privado, institutos tecnológicos e comunidade científica." Nos segmentos específicos localizados no PIM, as inovações parecem depender fortemente do esforço exógeno em $\mathrm{P} \& \mathrm{D}$, visto que boa parte é de indústrias internacionalmente concentradas. Portanto, como prevê a PDP, avanços maiores nestes segmentos dependem de maior engajamento e coordenação com o setor privado e com o meio acadêmico-científico. Há também um esforço local nessa direção, como na criação, pela Universidade Federal do Amazonas em 2005, do Centro de Pesquisa e Desenvolvimento de Tecnologia Eletrônica e da Informação e, pela Universidade do Estado do Amazonas em 2014, tanto de uma filial do laboratório Samsung Ocean quanto do Laboratório de Robótica e Automação Industrial, todos em parcerias com empresas do PIM.

A não inclusão de certos segmentos industriais do PIM nas prioridades da política industrial pode decorrer de inúmeros fatores, mas nos detemos a dois. Um abrange as empresas que lá se instalaram no passado em função exclusiva dos 
benefícios fiscais, como é o caso das bicicletas. Essas indústrias, classificadas como scale-intensive, geram renda e emprego, mas sua capacidade de inovar com maiores retornos e gerar spillover é limitada. No caso particular das bicicletas, as mudanças de maior impacto recente foram a introdução dos quadros de alumínio, no início da década de 1990, e a expansão das bicicletas com câmbio e dos modelos híbridos com motor elétrico, ao longo dos anos 2000. Nenhum dos três componentes componentes consta no PPB das bicicletas (BRASIL, 2012c).

Outro fator envolve a dinâmica de adaptação das empresas à abertura comercial nos anos 1990. Algumas firmas localizadas no centro-sul deslocaram a produção ou parte dela para o PIM em busca de competitividade, mesmo que espúria, para competir com bens importados. Assim, certos segmentos estão no PIM por estratégias empresariais autônomas. Ou seja, sua presença no PIM tem a ver mais com rearranjo em seus mercados em função da dinâmica de concorrência global e não com uma política industrial em si. Estar instalada no PIM e gerar encadeamentos no processo produtivo não significa, porém, ter adquirido competitividade estrutural e desistido de suas plantas no centro-sul. Dependendo do PPB da atividade, é possível que os produtos finais nacionais (não só os produzidos dentro do PIM) sejam feitos com elevado conteúdo de desnacionalização, como já visto. Ou seja, a relocalização no PIM não gera competitividade estrutural, mas cria linhas de montagem com alto volume de partes e peças importadas sem necessariamente criar uma cadeia industrial nacional.

Dois aspectos relevantes surgem a partir dessa dinâmica das empresas. Um é o fenômeno da atração de firmas estrangeiras. Empresas que exportam em CKD ou SKD para o Brasil continuam a fazê-lo, mas passam a ter que negociar sua entrada no país como investimento direto. Trata-se de algo conhecido desde o período da substituição de importações. O importador atrai seu fornecedor estrangeiro como concorrente nacional, o que é positivo do ponto de vista da competição. O segundo aspecto refere-se ao enraizamento da produção nacional, que requer um relacionamento pervasivo com o respectivo complexo produtivo. Ou seja, a produção nacional deve implicar certo grau de complexidade de processos e componentes finais produzidos no país de modo a não favorecer apenas empresas maquiladoras.

Como visto, o PPB tentar lidar com o problema, e hoje é válido também para os bens contemplados na Lei de Informática. O PPB de tablets ilustra bem os desafios expostos (BRASIL, 2011b). Ele exige a montagem local de componentes importantes, como os de processamento na placa de circuito e a sua integração aos componentes mecânicos e elétricos. Gabinetes e baterias foram dispensados sem data 
definida. A montagem das telas foi dispensada até o final de 2013, mas estendida em revisão do PPB em 2014 "(a)té que haja efetiva produção no País” (BRASIL, 2014a). Além disso, os tablets foram incluídos na Lei de Informática pela Medida Provisória n. 534/2011 e pela Lei n. 12.507/2011. A reação a tais instrumentos refletiu as preocupações apontadas acima. Em entrevista, o pesquisador do Ipea João Maria de Oliveira afirmou: "Simplesmente importar uma indústria para começar a produzir este tipo de equipamento, que tem, de fato, demanda em larga escala, o valor adicionado não vai ficar aqui" (COSTA, 2011). Não obstante, o governo do Estado de São Paulo manifestou incômodo na época, temendo que tais ações ocorressem em detrimento a investimentos do segmento em seu território (STF, 2011). Isso indica que a sobreposição das políticas teve um potencial de impacto na dinâmica de localização da indústria, ao menos no que se refere às etapas scale-intensive exigidas pelo PPB.

Em princípio, setores mais dinâmicos em termos de capacitações e inovação, por um lado, tenderiam a ver no PPB um motivo para internalizar mais etapas ou componentes do seu processo produtivo. No entanto, o caráter consensual da homologação dos PPB permite que empresas concorrentes retaliem o processo quando não têm as mesmas expectativas de ganhos ou se veem em desvantagem com relação à proponente. Assim, ações complementares de capacitação tecnológica, de financiamento, ou outros mecanismos de política industrial acessíveis às demais firmas do segmento industrial envolvido podem potencializar os PPB. A empresa proponente trocaria a desvantagem de ver as demais criando obstáculos à homologação do PPB pela desvantagem de vê-las tendo acesso a recursos que promovem o catching up. Ou seja, troca-se a situação que desfavorece o incremento da cadeia produtiva no PIM por uma mais favorável, enquanto o diferencial entre a proponente e as demais não se altera substancialmente nos termos da política. Caberia aos GT-PPB, por exemplo, avaliar também as dimensōes em que tais recursos de política industrial poderiam ser oferecidos, de modo a pressionar e incentivar as demais firmas a incrementar seus processos produtivos no PIM. Por outro lado, esses setores mais dinâmicos em termos de capacitações e inovação trazem um desafio adicional ao mecanismo de PPB. Por contemplarem mudanças mais frequentes e sofisticadas em termos de conhecimentos, eles exigem que os GT-PPB tenham acesso a competências elaboradas e confiáveis, com vistas a avaliá-las com rapidez. Isso implica também atentar para as competências administrativas e jurídicas que resguardam os processos de óbices judiciais, por exemplo. 


\section{Comentários finais}

A complexidade das economias modernas traz novos desafios tanto à coordenação da produção entre e dentro de empresas e mercados quanto à atuação do setor público na formulação e implementação de políticas. Aqui consideramos a questão da convergência entre políticas industriais (PDP e PBM) e de desenvolvimento regional (o caso do PIM) e a possibilidade de sua sobreposição ter efeitos potencializadores.

Viu-se que, em termos numéricos, boa parte dos segmentos industriais do PIM é contemplada pela PDP e pelo PBM. Suas etapas produtivas no PIM são intensivas em escala, aquém da vanguarda das capacitaçôes tecnológicas, e consumidoras vorazes do complexo eletrônico, cujo potencial inovativo e de spillover lhes é superior. A efetivação desse potencial, porém, não tem se dado necessariamente no país ou na região aqui estudada, mas sim nas matrizes internacionais das empresas instaladas. Em última instância, estas etapas, embora sejam pouco intensivas em inovação local, estão em segmentos de razoável resposta à renda e cuja indústria é intensiva em conhecimento e inovação. Cabe ver se as políticas trabalham sobre esse potencial.

Sob esta ótica, três segmentos do PIM parecem mais propícios aos efeitos da interseção das políticas em prol de sua expansão local. Um é o de duas rodas, intensivo em escala numa indústria já madura. Outro é o de bens de informática, cujas atividades localizadas no PIM abarcam a parte intensiva em escala dos diferentes nodos do complexo industrial, como ilustra o PPB dos tablets. Por fim, há também o incipiente segmento de biocosméticos, que contempla ligaçôes com setores estratégicos da PDP - os de bio e de nanotecnologias. Sua efetivação, porém, depende da construção e fixação de competências locais, exigindo coordenação e convergência com outros esforços de políticas públicas, o que resta a ver.

\section{Referências bibliográficas}

AZEVEDO, C. A regulamentação do acesso aos recursos genéticos e aos conhecimentos tradicionais associados no Brasil. Biota Neotropica, v. 5, n. 1, p. 1-9, 2005.

BECKER, B. Geopolítica da Amazônia. Estudos Avançados, v. 19, n. 53, p. 71-86, 2005.

BRASIL. Ministério do Desenvolvimento, Indústria e Comércio Exterior - MDIC. Política de Desenvolvimento Produtivo. Inovar e investir para sustentar o crescimento. Brasília, 2008. 
Disponível em: <http://www.desenvolvimento.gov.br/pdp/index.php/sitio>. Acesso em: 09 no, 2009.

Ministério do Desenvolvimento, Indústria e Comércio Exterior - MDIC. Política de Desenvolvimento Produtivo. Conheça a PDP. Brasília, 2009. Disponível em: <http:// www.pdp.gov.br/paginas/conheca_pdp.aspx?path=Conhe\%C3\%A7a\%20a\%20PDP>. Acesso em: 09 nov. 2009.

Ministério do Desenvolvimento, Indústria e Comércio Exterior - MDIC. $O$ que é o PPB? Brasília, 2011a. Disponível em: <http://www.mdic.gov.br/sitio/interna/interna. php?area=2\&menu=1103>. Acesso em: 15 mar. 2011.

- Ministério do Desenvolvimento, Indústria e Comércio Exterior - MDIC; Ministério da Ciência e Tecnologia - MCT. Portaria Interministerial no 127, de 31 de maio de 2011. Brasília, 2011b.

. Ministério do Desenvolvimento, Indústria e Comércio Exterior - MDIC. Política de Desenvolvimento Produtivo. Programas. Brasília, 2012a. Disponível em: <http:// www.pdp.gov.br/Paginas/Default.aspx>. Acesso em: 20 abr. 2012.

Ministério do Desenvolvimento, Indústria e Comércio Exterior - MDIC. Plano Brasil Maior. Dimensão setorial. Brasília, 2012b. Disponível em: <http://www.brasilmaior. mdic.gov.br/conteudo/153>. Acesso em: 20 abr. 2012.

Ministério do Desenvolvimento, Indústria e Comércio Exterior - MDIC; Ministério da Ciência e Tecnologia - MCT. Portaria Interministerial no 63, de 28 de fevereiro de 2012. Brasília, 2012c.

Ministério do Desenvolvimento, Indústria e Comércio Exterior - MDIC. Política de Desenvolvimento Produtivo. Programas para destaque estratégicos. Brasília, s/d "a". Disponível em: <http://www.mdic.gov.br/pdp/index.php/sitio/conteudo/index/5>. Acesso em: 10 nov. 2014.

Ministério do Desenvolvimento, Indústria e Comércio Exterior - MDIC. Plano Brasil Maior. Plano Brasil Maior chega aos Estados. Brasília, s/d "b”. Disponível em: <http:// www.brasilmaior.mdic.gov.br/conteudo/287\#>. Acesso em: 10 nov. 2014.

Ministério do Desenvolvimento, Indústria e Comércio Exterior - MDIC; Ministério da Ciência, Tecnologia e Inovação - MCT. Portaria Interministerial n ${ }^{\circ} 110$, de 29 de maio de 2014. Brasília, 2014a.

Presidência da República. Emenda Constitucional $n^{\circ}$ 83, de 5 de agosto de 2014. Brasília: Casa Civil, 2014b. 
Presidência da República. Medida Provisória no 2.186-16, de 23 de agosto de 2001. Brasília: Casa Civil, 2001.

CHANG, H-J. Industrial policies in the 21st Century. In: INTERNATIONAL CONFERENCE ON INDUSTRIAL POLICIES IN THE 21ST CENTURY - CELEBRATING BNDES 60TH ANNIVERSARY. Anais... Rio de Janeiro, 10-11 de maio 2012.

COOKE, P. Regional innovation systems. Geoforum, v. 23, n. 3, p. 365-382, 1992.

. Complex adaptive innovation systems. Londres: Routledge, 2012.

COSTA, G. Especialista acredita que Brasil conseguirá só montar tablets, sem produção de componentes. Agência Brasil, 4 de junho de 2011. Disponível em: <http://agenciabrasil. ebc.com.br/noticia/2011-06-04/especialista-acredita-que-brasil-conseguira-so-montar-tablets-sem-producao-de-componentes>. Acesso em: 03 jan. 2014.

CUNHA, A. As novas cores da linha branca: os efeitos da desnacionalização da indústria brasileira de eletrodomésticos nos anos 1990. Tese (Doutorado) Campinas: IE/Unicamp, 2003.

DINIZ, C.; CROCCO, M. Reestruturação econômica e impacto regional: o novo mapa da indústria brasileira. Nova Economia, v. 6, n. 1, p. 77-103, 1996.

DINIZ, M. A dinâmica das inovaçôes nas empresas do pólo industrial de Manaus. Tese (Doutorado) Belém: NAEA/UFPA, 2008.

FERRARI FILHO, F.; PAULA, L. Regime cambial, conversibilidade da conta de capital e performance econômica: a experiência recente de Brasil, Rússia, Índia e China. In: SICSÚ, J.; FERRARI FILHO, F. (Eds.). Câmbio e controles de capitais. Rio de Janeiro: Elsevier-Campus, 2006, p. 184-221.

FERREIRA, S.; SAMPAIO, M. (Orgs.). Biodiversidade e conhecimentos tradicionais associados. Brasília: SBPC, 2013.

FERREIRA, S.; BOTELHO, L. O emprego industrial na Região Norte: o caso do Polo Industrial de Manaus. Estudos Avançados, v. 28, n. 81, p.141-54, 2014.

LASMAR, D. Valorização da biodiversidade: capacitação e inovação tecnológica na fitoindústria no Amazonas. Tese (Doutorado). Rio de Janeiro: UFRJ-Coppe, 2005.

LEMOS, M.; DINIZ, C.; GUERRA, L.; MORO, S. A nova configuração regional brasileira e sua geografia econômica. Estudos Econômicos, v. 33, n. 4, p. 665-700, 2003.

MARIA, T. Após prorrogação da Zona Franca de Manaus, CBA aguarda 'empurrãozinho'. Jornal do Commercio, 21 de julho de 2014. Disponível em: <http://www.portalamazonia.com. br/editoria/ciencia-e-tecnologia/apos-prorrogacao-da-zona-franca-de-manaus-cba-aguarda-empurraozinho/>. Acesso em: 05 nov. 2014. 
MASKELL, P.; MALMBERG, A. Local learning and industrial competitiveness. Cambridge Journal of Economics, v. 23, p. 167-85, 1999.

MORGAN, K. The learning region: institutions, innovations and regional renewal. Regional Studies, v. 31, n. 5, p. 491-503, 1997.

PAVITT, K. Sectoral patterns of technical change: towards a taxonomy and a theory. Research Policy, v. 13, p. 343-373, 1984.

PERTICARRARI, D. Reestruturação produtiva e emprego na induistria de linha branca no Brasil. Dissertação (Mestrado) Campinas: IG/Unicamp, 2003.

PORTAL BRASIL. Projeto de parque tecnológico do Polo de Manaus será apresentado nesta quinta. Brasília, 2014. Disponível em: <http:/www.brasil.gov.br/ciencia-e-tecnologia/2010/12/projeto-de-parque-tecnologico-do-polo-de-manaus-sera-apresentado-nesta-quinta>. Acesso em: 20 nov. 2014.

RIOS, L. Secretário do MDIC visita microempresas de cosméticos no DIMPE. Manaus, 2012. Disponível em: <http://www.suframa.gov.br/suf_pub_noticias.cfm?id=13414>. Acesso em: 27 dez. 2013.

SUFRAMA - Superintendência da Zona Franca de Manaus. Modelo Zona Franca. O que é o projeto ZFM? Manaus, 2009a. Disponível em: <http://www.suframa.gov.br/zfm_o_ que_e_o_projeto_zfm.cfm>. Acesso em: 10 nov. 2009.

Modelo Zona Franca. Indústria. Manaus, 2009b. Disponível em: <http://www. suframa.gov.br/zfm_industria.cfm>. Acesso em: 10 nov. 2009.

. Modelo Zona Franca. Indicadores do PIM 2004-2009. Manaus, 2009c. Disponível em: <http://www.suframa.gov.br/zfm_indicadores_do_pim.cfm>. Acesso em: 10 nov. 2009. Modelo Zona Franca. Indicadores do PIM 1998-2010. Manaus, 2010. Disponível em: <http://www.suframa.gov.br/zfm_indicadores_do_pim.cfm>. Acesso em: 23 nov. 2012. . Modelo Zona Franca. Desenvolvimento regional sustentável. Manaus, 2013 a. Disponível em: <http://www.suframa.gov.br/zfm_desenvolvimento_regional.cfm>. Acesso em 11 dez. 2013.

Indicadores de desempenho do Polo Industrial de Manaus 2008-2013. Manaus, 2013b. Disponível em: <http://www.suframa.gov.br/download/indicadores/RelOUTUBRO\%20FINAL_10_2013-28_11_2013-08_19_03.pdf>. Acesso em 27 dez. 2013.

STF - Supremo Tribunal Federal. Amazonas contesta norma de SP de incentivo na produção de 'tablets". Notícias STF, 28 de julho de 2011. Disponível em: <http://www.stf.jus.br/portal/ cms/verNoticiaDetalhe.asp?idConteudo=185231>. Acesso em: 03 jan. 2014. 
SUZIGAN, W. Empresas transnacionais e internacionalização da P\&D: elementos de organização industrial da economia da inovação. Resenha. Revista de Economia Política, v. 28, n. 2-110, p. 358-60, 2008.

WALDROP, M. Complexity: the emerging science at the edge of order and chaos. Londres: Viking, 1992. 